\title{
Morphology and Composition of Inclusions in Si-Mn Deoxidized Steel at the Solid-Liquid Equilibrium Temperature
}

\author{
Jonah GAMUTAN, ${ }^{*}$ Takahiro MIKI and Tetsuya NAGASAKA \\ Department of Metallurgy, Graduate School of Engineering, Tohoku University, Sendai, 980-8579 Japan. \\ (Received on May 21, 2019; accepted on July 26, 2019)
}

\begin{abstract}
Morphology and composition of inclusions change with temperature. However, besides the temperature conditions during steelmaking or continuous casting, other factors contributing to changes in the morphology and composition of inclusions during solidification are still unknown. In this study, the formation of complex inclusions in Si-Mn deoxidized steel after isothermal holding at the solid-liquid equilibrium temperature $\left(T_{S}\right)$ was investigated.

The typical inclusions found in the alloy were $\mathrm{MnO}-\mathrm{SiO}_{2}$ based, spherically shaped and homogeneously distributed. With isothermal holding at the solid-liquid equilibrium temperature, formation of a secondary $\mathrm{SiO}_{2}$-rich inclusion phase occurred. The changes in the composition of the inclusions depended on the manganese and silicon contents in the metal.

The general mechanism of inclusion formation observed in this study can be divided into three steps: 1) the formation of primary $\mathrm{MnO}-\mathrm{SiO}_{2}$ inclusions above the liquidus temperature when the steel is in a completely molten state as a result of the deoxidation process; 2 ) the nucleation of secondary inclusions as the molten steel becomes supersaturated with the solute elements while holding at the solid-liquid equilibrium temperature; and 3) the growth and coalescence of inclusions due to natural convection in the molten alloy. From this, the inclusions formed in Si-Mn deoxidized alloys held isothermally at the solidliquid equilibrium temperature were of three types: primary $\mathrm{MnO}-\mathrm{SiO}_{2}$ inclusions, secondary $\mathrm{SiO}_{2}$ inclusions and complex inclusions with both primary $\mathrm{MnO}-\mathrm{SiO}_{2}$ inclusions and precipitated secondary $\mathrm{SiO}_{2}$ inclusions.
\end{abstract}

KEY WORDS: Si-Mn deoxidation; complex inclusion formation; solid-liquid equilibrium temperature; microsegregation.

\section{Introduction}

One of the unavoidable and persisting challenges to steel production is the control of harmful non-metallic inclusions that form during the steelmaking process. Recent approaches to this problem involve modifying the inclusions to optimize the properties of the steels or minimizing the amount of inclusions to nullify their detrimental effects on the steel. ${ }^{1)}$ To accomplish either of these entails a thorough understanding of the origin, phases, morphology and composition of inclusions in all the stages of steelmaking from ladle treatment and casting to the final stages of rolling.

Depending on their thermal origin, inclusions can be classified as primary or secondary. Primary inclusions are formed under isothermal conditions during the deoxidation process while secondary inclusions are generated during solidification and cooling. ${ }^{2)}$ During deoxidation, the dissolved oxygen in molten steel is precipitated as oxides due to the addition of elements with high oxygen affinity. One of the most common deoxidation methods utilizes silicon in combination with manganese. In $\mathrm{Si}-\mathrm{Mn}$ deoxidation,

\footnotetext{
* Corresponding author: E-mail: jonah.gamutan@gmail.com DOI: https://doi.org/10.2355/isijinternational.ISIJINT-2019-313
}

the products are mainly $\mathrm{MnO}$ and $\mathrm{SiO}_{2}$. Compared to other deoxidants, $\mathrm{Si}-\mathrm{Mn}$ complex deoxidation yields lower residual oxygen in steel due to the reduced activity of silicon dioxide by the addition of manganese. ${ }^{3)}$ It also avoids the formation of harmful $\mathrm{Al}_{2} \mathrm{O}_{3}$ that forms during $\mathrm{Al}$ deoxidation. Ferrosilicon and ferromanganese used in $\mathrm{Si}-\mathrm{Mn}$ deoxidation are also relatively cheap and are more readily available than other deoxidizing agents.

Several studies on the thermodynamics of $\mathrm{Si}-\mathrm{Mn}$ deoxidation and inclusion formation have been reported. ${ }^{4-11)}$ The deoxidation product is basically $\mathrm{MnO}-\mathrm{SiO}_{2}$ with a little $\mathrm{FeO}$, but for the sake of simplicity can be considered as pure $\mathrm{MnO}-\mathrm{SiO}_{2}$. It has also been reported that the composition of the deoxidation product is regulated by the silicon to manganese ratio in the alloy. ${ }^{3)}$ From the viewpoint of minimizing the harmful effects of inclusions in steel, it is desirable for these inclusions to be soft and have a low melting point. Kang et al. found that the $\mathrm{MnO} / \mathrm{SiO}_{2}$ ratio and $\mathrm{Al}_{2} \mathrm{O}_{3}$ content are key points in controlling the liquidus temperature and primary phase of the inclusion. ${ }^{4)}$ Moreover, regulating $\mathrm{Al}_{2} \mathrm{O}_{3}$ content of inclusions using $\mathrm{Si}-\mathrm{Mn}$ deoxidation may be done by keeping at the target composition until complete solidification and by forming inclusions that remain stable even during cooling. ${ }^{9)}$ It was also found that in the $\mathrm{MnO}$ 
$\mathrm{SiO}_{2}-\mathrm{TiO}_{2}$ oxide system at $1400^{\circ} \mathrm{C}$, interaction between $\mathrm{MnO}$ and $\mathrm{SiO}_{2}$ is the strongest. ${ }^{11)}$

Aside from this, it is well known that morphology and composition of inclusions change with temperature. ${ }^{12-16)}$ In a study by Zhuo et al., MnS precipitation around an oxide phase was observed in furnace-cooled $\mathrm{Mn}-\mathrm{Si}-\mathrm{Ti}$ deoxidized steel. This was found to promote the formation of an intragranular ferrite structure, which can provide a suitable combination of properties in steel by grain refinement. ${ }^{12)}$ The optimum composition at which $\mathrm{MnS}$ can readily precipitate in $\mathrm{Si}-\mathrm{Mn}$ deoxidized steel was determined by Kim et al. using a thermodynamic computational technique and verified by experimental data. ${ }^{16)} \mathrm{MnS}$ precipitation on a primary oxide phase was also found to improve by isothermal holding at $1200^{\circ} \mathrm{C}$ in $\mathrm{Mn}-\mathrm{Si}-\mathrm{Ti}$ deoxidized steel. ${ }^{5)}$

At this point, although the thermodynamics of inclusion formation by $\mathrm{Si}-\mathrm{Mn}$ deoxidation at the steelmaking temperature and the continuous casting temperature has already been well studied, steelmakers still find it difficult to predict the type of inclusions that remain in steel after solidification. The authors believe that other factors, such as changes in the morphology and composition of inclusions at the solid-liquid equilibrium temperature, play an important role in the evolution of inclusions. Without this knowledge, a comprehensive understanding of inclusion behavior cannot be achieved.

In this study, the authors are particularly interested in the behavior of inclusions at the solid-liquid equilibrium temperature due to the microsegregation that occurs at this temperature. During solidification, a segregation profile develops within the microstructure of steel due to solute rejection by the solidifying alloy. This leads to enrichment of the solute in the liquid, which may cause formation of new inclusions and transformation of existing ones. A previous study by Fujisawa et al. investigated the distribution of silicon and oxygen in the molten zone and solidified metal at the solid-liquid equilibrium temperature using a zone melting technique. At the molten zone, silicon and oxygen concentrations were found to be higher than that in the solid phase due to rejection of solutes from the solid. These conditions create a highly favorable environment for reaction between the solutes, which may lead to nucleation of silica. ${ }^{17)}$ A coupled mathematical model of microsegregation and inclusion precipitation also showed that precipitation of inclusions in silicon steel occurs simultaneously as a result of the solute enrichment, which eventually suppresses the segregation degree of solute elements during solidification. ${ }^{18)}$ It was also found that during the later stages of solidification in semi-killed steels, inclusions close to $\mathrm{SiO}_{2}$ saturation may form as a result of microsegregation. ${ }^{19)}$

Given the prevailing scenario, the purpose of our current work is to examine the formation of complex inclusions in $\mathrm{Si}-\mathrm{Mn}$ deoxidized steel in terms of morphology, size and composition after isothermal holding at the solid-liquid equilibrium temperature $\left(\mathrm{T}_{\mathrm{s}}\right)$ and to elucidate a mechanism to explain inclusion behavior at this temperature. In this study, the solid-liquid equilibrium temperature is defined as the temperature at which the solidified alloy and molten metal co-exist during solidification. It is the two-phase region found between the liquidus and the solidus of a given alloy.

\section{Experimental Procedure}

In order to observe the evolution of inclusions in $\mathrm{Si}-\mathrm{Mn}$ deoxidized steel during solidification, steel samples with varying silicon and manganese additions were prepared in a vertical resistance furnace by isothermal holding at the solid-liquid equilibrium temperature.

\subsection{Preparation of the Alloy}

The morphology and composition of inclusions were investigated using a direct method of forming inclusions in liquid steel. As illustrated schematically in Fig. 1, about $25 \mathrm{~g}$ of $\mathrm{Fe}-\mathrm{Mn}-\mathrm{Si}$ alloy was prepared in an $\mathrm{Al}_{2} \mathrm{O}_{3}$ crucible placed in an outer $\mathrm{MgO}$ crucible. Electrolytic iron with reagent grade metallic manganese flake, silicon lump and $\mathrm{Fe}_{2} \mathrm{O}_{3}$ powder were weighed and mixed at the target compositions. The samples were then placed inside the vertical resistance furnace and heated to $1550^{\circ} \mathrm{C}$ to achieve equilibrium using a pre-determined heating pattern under 400 $\mathrm{cm}^{3} / \mathrm{min}$ of purified argon gas atmosphere that was passed through a gas drying unit. The actual sample temperature was monitored using a Pt-Rh thermocouple positioned just below the stage inside the furnace. After heating, the samples were quickly taken out of the furnace and quenched using helium gas.

\subsection{Heating and Composition}

To determine the behavior of inclusions at the solidliquid equilibrium temperature, samples were heated using the heating pattern as illustrated in Fig. 2. The first step involved heating to $1550^{\circ} \mathrm{C}$ and then holding to achieve equilibrium. Subsequently, the temperature of the furnace was lowered to the solid-liquid equilibrium temperature and then held for 1 hour. The samples were then quickly taken out of the furnace and quenched.

The composition of the alloy was subsequently varied with varying manganese and silicon contents as indicated in Table 1. Solid-liquid equilibrium temperature $\left(T_{\mathrm{s}}\right)$ at

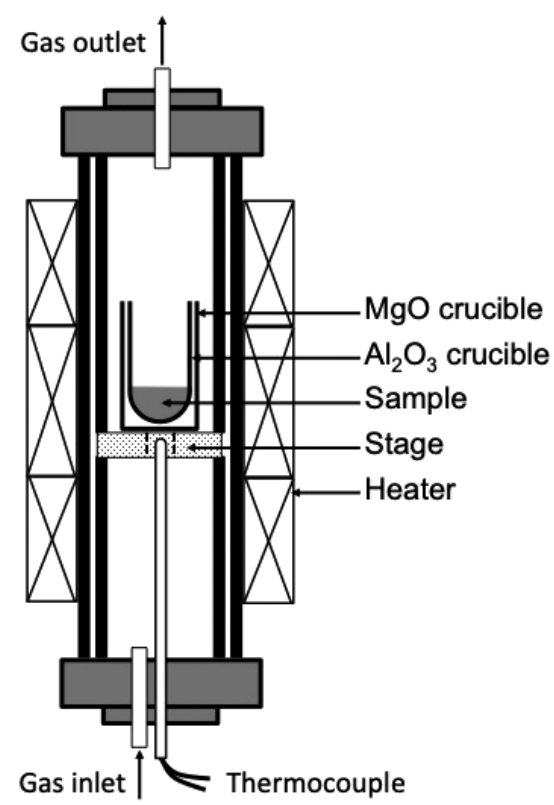

Fig. 1. Schematic diagram of the vertical resistance furnace used in heating experiments. 


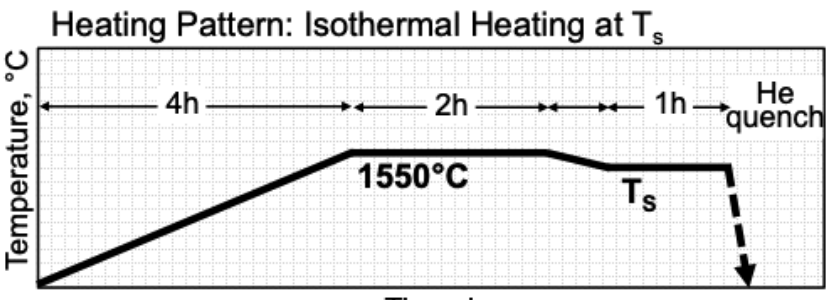

Time, $\mathrm{h}$

Fig. 2. Heating pattern used in this study.

Table 1. Metal phase composition, calculated solidification temperature of the alloys and estimated activities of $\mathrm{MnO}$ and $\mathrm{SiO}_{2}$.

\begin{tabular}{ccccccc}
\hline $\begin{array}{c}\text { Sample } \\
\text { No. }\end{array}$ & $\begin{array}{c}{[\mathrm{Mn}]} \\
\text { mass } \%\end{array}$ & $\begin{array}{c}{[\mathrm{Si}]} \\
\text { mass } \%\end{array}$ & $\begin{array}{c}{[\mathrm{O}]} \\
\mathrm{ppm}\end{array}$ & $\begin{array}{c}\mathrm{T}_{\mathrm{s}} \\
\left({ }^{\circ} \mathrm{C}\right)\end{array}$ & $\mathrm{a}_{\mathrm{MnO}}$ & $\mathrm{a}_{\mathrm{SiO}_{2}}$ \\
\hline 1 & 0.706 & 0.056 & 41.00 & 1532.70 & 0.573 & 0.196 \\
2 & 0.719 & 0.095 & 37.83 & 1532.13 & 0.540 & 0.217 \\
3 & 0.566 & 0.144 & 48.75 & 1531.56 & 0.484 & 0.259 \\
4 & 0.616 & 0.179 & 41.24 & 1530.99 & 0.480 & 0.262 \\
5 & 0.647 & 0.219 & 32.72 & 1530.42 & 0.474 & 0.268 \\
6 & 0.282 & 0.083 & 57.50 & 1533.55 & 0.438 & 0.305 \\
7 & 0.417 & 0.096 & 52.10 & 1533.08 & 0.473 & 0.269 \\
8 & 0.311 & 0.086 & 53.28 & 1532.60 & 0.447 & 0.296 \\
9 & 0.516 & 0.105 & 45.40 & 1531.66 & 0.492 & 0.252 \\
\hline
\end{tabular}

different $\mathrm{Mn}$ and Si compositions was calculated using the equation obtained by Fujisawa et al., for $\mathrm{Fe}-\mathrm{Mn}-\mathrm{Si}$ ternary system:

$$
T_{s}\left({ }^{\circ} \mathrm{C}\right)=1538-4.73\left[\% M n_{(l)}\right]-11.4\left[\% \mathrm{Si}_{(l)}\right]
$$

where $\left[\% M n_{(\ell)}\right]$ and $\left[\% \mathrm{Si}_{(\ell)}\right]$ are the manganese and silicon compositions of the liquid phase, respectively. ${ }^{20)}$ Strictly speaking, the present system is an $\mathrm{Fe}-\mathrm{Mn}-\mathrm{Si}-\mathrm{O}$ quaternary system. However, the oxygen content in the molten phase is considerably low. Hence, the effect of oxygen can be neglected. Calculated solid-liquid equilibrium temperature values using Eq. (1) were also verified using the single point equilibrium module of Thermo-Calc Software, this time as an $\mathrm{Fe}-\mathrm{Mn}-\mathrm{Si}-\mathrm{O}$ quaternary system. Solid-liquid equilibrium temperature values were found to be in good agreement with each other and are listed in Table 1.

\subsection{Characterization}

Metal phase composition after heating was determined by ICP-AES (Inductively Coupled Plasma - Atomic Emission Spectroscopy). About $1.0 \mathrm{~g}$ of the alloy was dissolved in $10 \mathrm{ml}$ of aqua regia solution prepared by mixing 3 parts of concentrated $\mathrm{HCl}$ to 1 part concentrated $\mathrm{HNO}_{3}$ for at least 6 hours. After confirming through visual inspection that the alloy has been completely dissolved, the resulting solutions were filtered, diluted with distilled water and then analyzed for silicon and manganese contents. The oxygen content of the alloy was determined by an inert gas fusion technique using LECO-ONH836 Oxygen/Nitrogen/Hydrogen Element Analyzer. For the analysis, 0.5 to 1.0 gram alloy samples were cut and polished using $\mathrm{SiC}$ paper with water up to $\# 600$ grit and cleaned using an ultrasonic bath in an anhydrous ethanol solution between every polishing step to remove surface contamination.

The determination of inclusion morphology and composition was performed using SEM-EDS (Scanning Electron Microscopy with Energy Dispersive X-ray Spectroscopy) analysis. The alloys were cut longitudinally along the center and hot-mounted using a carbon filler resin. It was then wet polished with an automatic polisher using a series of $\mathrm{SiC}$ paper from $\# 80$ grit up to $\# 4000$ grit. Inclusion size and morphology was determined using the built-in image analysis tool in the SEM software. The composition of the inclusions was measured using EDS combined with an image analysis technique to ensure the quality and accuracy of measurements. ${ }^{5)}$ A minimum of 30 inclusions were examined in each sample using an acceleration voltage (AV) of $20 \mathrm{kV}$, a working distance (WD) of $15 \mathrm{~mm}$ and a spot size (SS) of $60 \mathrm{~nm}$. To obtain the average composition of the inclusion, a point analysis of at least 5 spots per inclusion was conducted. Finally, iron and oxygen were excluded from the quantitative results to eliminate the influence of stray signals from the pre-dominantly ferrous matrix and to avoid the inaccuracies associated with oxygen determination using SEM-EDS. Final quantitative values were normalized to $100 \%$ and reported in terms of mass percentage.

\section{Results and Discussion}

\subsection{Attainment of Equilibrium}

Initially, to determine the necessary time to achieve equilibrium at $1550^{\circ} \mathrm{C}$, a series of experiments was conducted for the Fe-1.0Mn-0.10Si (mass\%) alloy with varying reaction periods. The manganese, silicon and oxygen contents of the resulting alloys were measured as shown in Fig. 3. No significant changes in the composition of the metal phase was found when the sample was held for 2, 3 and 4 hrs, with almost constant values obtained. Hence, the equilibrium reaction time for the $\mathrm{Fe}-\mathrm{Mn}-\mathrm{Si}$ system at $1550^{\circ} \mathrm{C}$ was determined to be sufficient at $2 \mathrm{hrs}$.

As a $\mathrm{Si}-\mathrm{Mn}$ deoxidized alloy, oxygen content of the untreated samples at $1550^{\circ} \mathrm{C}$ was theoretically calculated based on E. T. Turkdogan while utilizing the thermodynamic parameters enlisted by Hino et al. ${ }^{3,21)}$ The following equilibrium relation is obtained for $\mathrm{Si}-\mathrm{Mn}$ deoxidation reaction:

$$
[\mathrm{Si}]+2(\mathrm{MnO})=2[\mathrm{Mn}]+\left(\mathrm{SiO}_{2}\right)
$$

Under equilibrium conditions the equilibrium constant can be expressed as,

$$
K=\left\{\frac{a_{M n}}{a_{M n O}}\right\}^{2} \frac{a_{S i O_{2}}}{a_{S i}}
$$

where

$$
\log K=-\frac{1510}{T}+1.27
$$

From Eq. (3), we can express the equilibrium constant in logarithmic form as,

$$
\log K=2 \log a_{M n}-\log a_{S i}+\log \frac{a_{S i O_{2}}}{a_{M n O}^{2}}
$$


where the activities of manganese and silicon can be expressed as the product of the activity coefficients, $f_{M n}$ and $f_{S i}$, and concentrations, $[\% \mathrm{Mn}]$ and $[\% \mathrm{Si}]$, respectively. Using Wagner's formalism at infinite dilution, deviation from Henry's Law can be accounted for by the introduction of the interaction parameter $(e)$ while considering the effects of silicon, manganese and oxygen as follows: ${ }^{22)}$

$$
\begin{aligned}
\log f_{S i} & =e_{S i}^{S i}[\% S i]+e_{S i}^{O}[\% O]+e_{S i}^{M n}[\% M n] \ldots \\
\log f_{M n} & =e_{M n}^{M n}[\% M n]+e_{M n}^{O}[\% O]+e_{M n}^{S i}[\% S i] .
\end{aligned}
$$

where the interaction parameters at $1600^{\circ} \mathrm{C}$ are found as in Table 2.

With a relatively small temperature difference, these interaction parameter values at $1600^{\circ} \mathrm{C}$ can also be applied to the temperatures used in this study. Activities of $\mathrm{MnO}$ and $\mathrm{SiO}_{2}$ at the solid-liquid equilibrium temperature were estimated from the measured metal phase composition by extrapolating the values from the results of Abraham et al. ${ }^{23)}$ Estimated values are listed in Table 1 and are plotted against $\mathrm{MnO}$ mole fraction values in Fig. 4. Compared to previous data, slightly different $\mathrm{MnO}$ and $\mathrm{SiO}_{2}$ activity values were obtained. ${ }^{23-27)}$ Nevertheless, estimated $\mathrm{MnO}$ and $\mathrm{SiO}_{2}$ activity values are deemed to be reasonable as $\mathrm{SiO}_{2}$ activity decreases with increasing $\mathrm{MnO}$ mole fraction.

Also, deoxidation equilibrium can be theoretically cal-

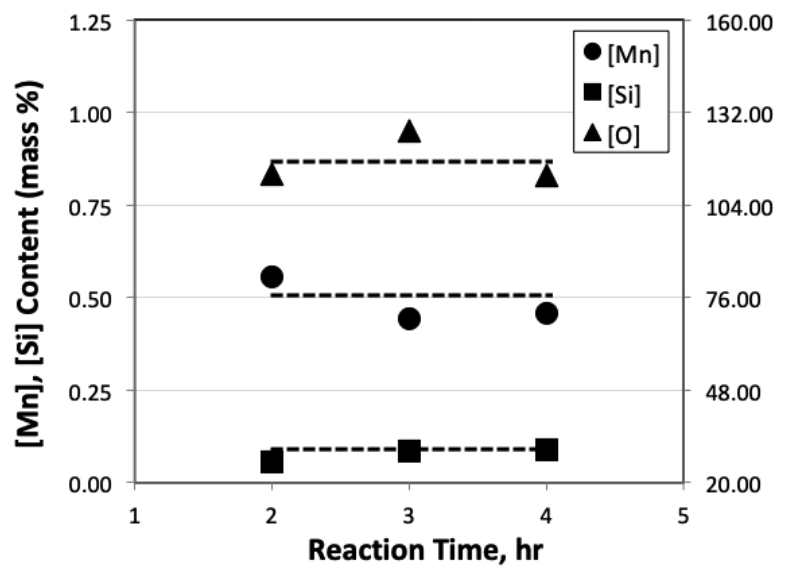

Fig. 3. $[\mathrm{Mn}]$, $[\mathrm{Si}]$ and $[\mathrm{O}]$ contents of $\mathrm{Fe}-1.0 \mathrm{Mn}-0.10 \mathrm{Si}$ (mass\%) alloy at $1550^{\circ} \mathrm{C}$ for various reaction times. culated from above as shown in Fig. 5. Experimental data after equilibrium heating for 2, 3 and 4 hours are also plotted here. Experimental deoxidation values seem to agree with the theoretical data well within the acceptable range in this type of work.

\subsection{Inclusion Formation at the Solid-liquid Equilib- rium Temperature}

\subsubsection{Morphology of Inclusions}

The typical microstructure of inclusions in Fe-1.0Mn-

Table 2. Interaction parameter values at $1600^{\circ} \mathrm{C}$.

\begin{tabular}{cccc}
\hline$i$ & $j$ & $e_{i}^{j}$ & Ref. \\
\hline \multirow{3}{*}{$\mathrm{Mn}$} & $\mathrm{Mn}$ & 0 & $28)$ \\
& $\mathrm{Si}$ & -0.0327 & $28)$ \\
& $\mathrm{O}$ & -0.138 & $29)$ \\
\hline $\mathrm{Si}$ & $\mathrm{Si}$ & 0.103 & $28)$ \\
& $\mathrm{Mn}$ & -0.0146 & $28)$ \\
\hline & $\mathrm{O}$ & -0.119 & $28)$ \\
\hline $\mathrm{O}$ & $\mathrm{O}$ & -0.17 & $28)$ \\
& $\mathrm{Mn}$ & -0.037 & $29)$ \\
& $\mathrm{Si}$ & -0.066 & $28)$ \\
\hline
\end{tabular}

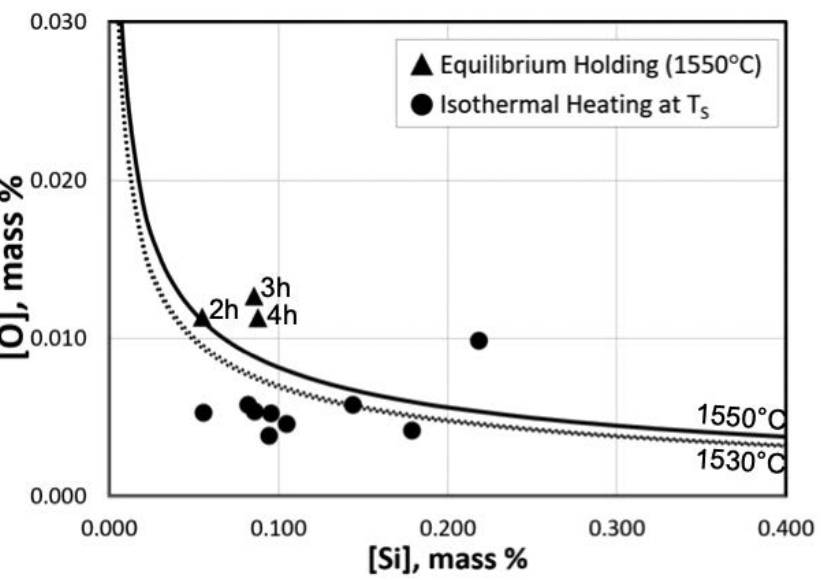

Fig. 5. Calculated deoxidation equilibrium at $1550^{\circ} \mathrm{C}$ plotted with experimental data

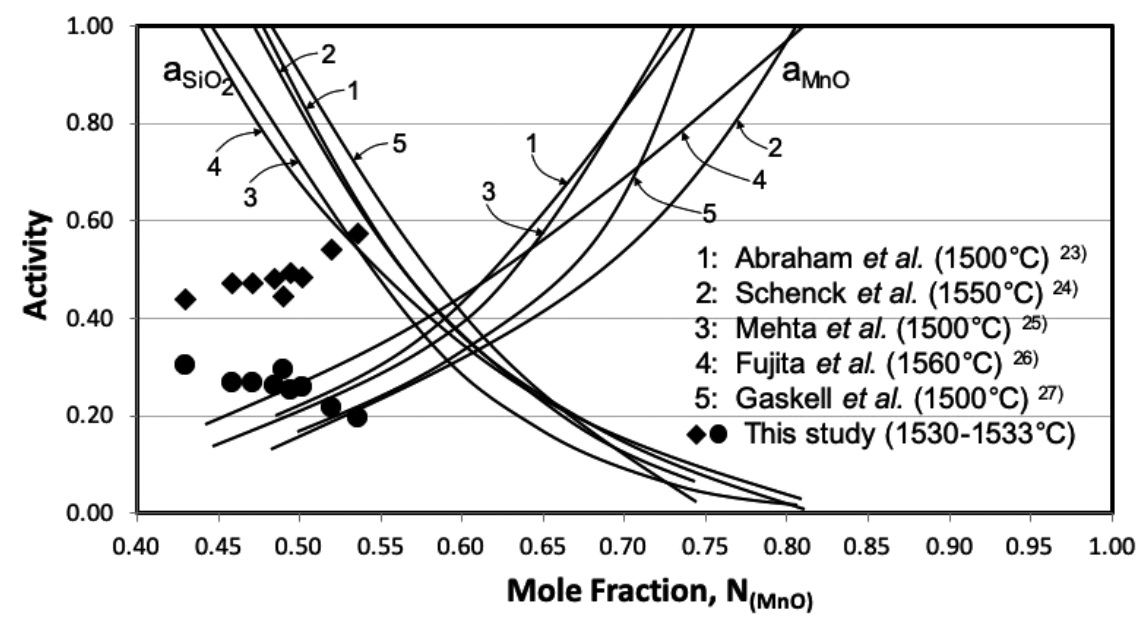

Fig. 4. Calculated $\mathrm{MnO}$ and $\mathrm{SiO}_{2}$ activities at the solid-liquid equilibrium temperature. 
$0.10 \mathrm{Si}$ (mass\%) alloy is shown in Fig. 6. All inclusions observed were spherical, uniformly distributed throughout the alloy and were composed largely of $\mathrm{MnO}-\mathrm{SiO}_{2}$. Without holding at the solid-liquid equilibrium temperature, spherical inclusions composed of a homogeneous primary inclusion phase formed under equilibrium conditions as indicated in Fig. 6(a). Contrary to this, inclusions that formed after isothermal heating at the solid-liquid equilibrium temperature for $1 \mathrm{hr}$ revealed the evolution of a darker $\mathrm{SiO}_{2}$-rich inclusion phase, in addition to the original homogenous primary inclusion phase, as shown in Fig. 6(b). As the SEM images show, the darker region formed at or near the boundary of the primary phase and the steel matrix. It appears to have initially formed independent of the primary phase and was appended at a later time.

As will be discussed in detail later, holding at the solidliquid equilibrium temperature where the solubility of the solute elements is different in both liquid and solid phases may have facilitated the formation of this darker secondary phase. In contrast, without lowering the temperature to the solid-liquid equilibrium temperature and by keeping the temperature at $1550^{\circ} \mathrm{C}$, the solubility of the solute elements did not reach its saturation point as the temperature of the alloy was maintained well above its melting point. Also, a rapid cooling rate of about an average of $250^{\circ} \mathrm{C} \mathrm{min}-1$ almost totally suppressed the precipitation of a secondary phase on the primary $\mathrm{MnO}-\mathrm{SiO}_{2}$ phase. With this, the darker $\mathrm{SiO}_{2}$-rich secondary phase can be considered to have formed as a secondary inclusion that precipitated during isothermal heating at the solid-liquid equilibrium temperature.

\subsubsection{Complex Inclusion Composition}

Compared with the primary inclusion phase, higher $\mathrm{SiO}_{2}$ content was observed in the secondary inclusion phase. It should be emphasized that independent $\mathrm{SiO}_{2}$ inclusions were not included in the measurement of composition. Although the primary phases of both Fe-1.0Mn-0.10Si (mass\%) alloys after heating showed an almost similar composition, the secondary phase that formed in isothermally held sample showed about 16 mass $\%$ difference in measured $\mathrm{SiO}_{2}$ content. In general, $\mathrm{MnO}-\mathrm{SiO}_{2}$ inclusions are desirable because of its almost homogeneous distribution in steel and its inability to form clusters. In addition, it has a very high deformability at temperatures above $1000^{\circ} \mathrm{C}$ and very low thermal expansion, which minimizes anisotropy, deforma-

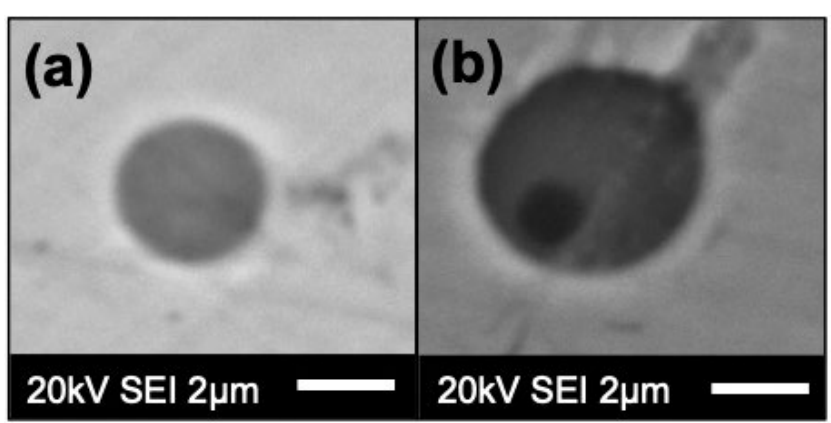

Fig. 6. Typical inclusion formed in $\mathrm{Fe}-1.0 \mathrm{Mn}-0.10 \mathrm{Si}$ (mass\%) alloy (a) after equilibrium holding at $1550^{\circ} \mathrm{C}$ and (b) with isothermal heating at the solid-liquid equilibrium temperature. tion and stress concentration in the alloy. ${ }^{30)}$

The dissolved oxygen content in the isothermally heattreated sample (37.83 ppm O) was lowered by almost half compared to the sample that was not held at the solid-liquid equilibrium temperature (73.80 ppm O). From this, it can be further deduced that these secondary inclusions did not form as primary deoxidation inclusions. A long holding time at the solid-liquid equilibrium temperature promoted increased deoxidation by the precipitation of the secondary inclusion phase. Theoretical data for deoxidation equilibrium at the solid-liquid equilibrium temperature is similarly plotted in Fig. 5 using the same method explained earlier. Experimental deoxidation data from the prepared alloys are also plotted in this figure. It should be noted, however, that the experimental data are not necessarily at equilibrium. Therefore, some deviation from theoretical values is expected.

\subsection{Varying $\mathrm{Mn}$ and $\mathrm{Si}$ Additions}

All $\mathrm{MnO}-\mathrm{SiO}_{2}$ inclusions were found to have a spherical shape, which is the most desirable inclusion morphology due to its very moderate effect on the mechanical properties of steel. The average size of the complex inclusions that formed after isothermal heat treatment $(3.45 \mu \mathrm{m})$ was found to be larger compared to the single-phase inclusions that formed without holding at the solid-liquid equilibrium temperature $(2.99 \mu \mathrm{m})$ as shown in Fig. 7. This increase in size can be attributed to the formation of a secondary phase that increased the effective area of the primary inclusion. In most cases, finer inclusions are wanted. The difference in the average diameter of inclusions in this study, however, is very small $(0.07$ to $0.56 \mu \mathrm{m})$ and may be irrelevant in terms of influencing the over-all mechanical properties of steel.

With isothermal heating at the solid-liquid equilibrium temperature, the precipitation of an $\mathrm{SiO}_{2}$-rich secondary phase was observed on the primary $\mathrm{MnO}-\mathrm{SiO}_{2}$ phase. Inclusion compositions of the prepared samples are listed in Table 3. The precipitation of a secondary $\mathrm{SiO}_{2}$-rich phase was observed in all alloys, except for Sample No. 1, which had the lowest silicon content at 0.056 mass $\%$.

Compositions of both primary and secondary phases changed according to manganese and silicon content in the metal phase, as indicated in Fig. 8. The $\mathrm{SiO}_{2}$ content of the inclusions decreased with the increase in manganese in the

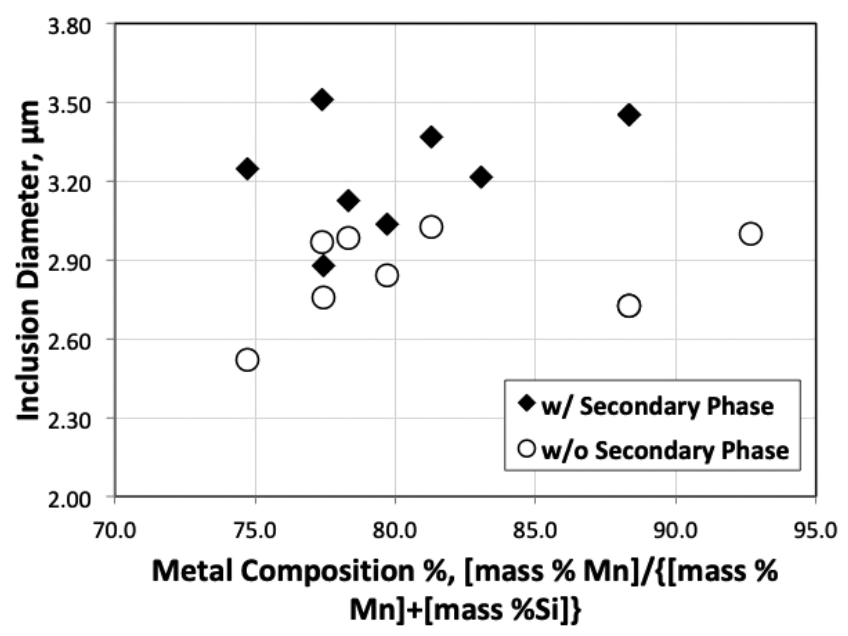

Fig. 7. Average inclusion diameter in each sample. 
Table 3. Inclusion phase composition of prepared $\mathrm{Si}-\mathrm{Mn}$ deoxidized samples.

\begin{tabular}{ccccc}
\hline Sample No. & \multicolumn{2}{c}{ Primary Inclusion } & \multicolumn{2}{c}{ Secondary Inclusion } \\
$(\mathrm{MnO})$ & $\left(\mathrm{SiO}_{2}\right)$ & $(\mathrm{MnO})$ & $\left(\mathrm{SiO}_{2}\right)$ \\
mass\% & mass\% & mass\% & 0 \\
\hline 1 & 57.69 & 42.31 & - & - \\
2 & 56.12 & 43.88 & 39.39 & 60.61 \\
3 & 54.35 & 45.65 & 36.23 & 63.77 \\
4 & 52.61 & 47.39 & 32.58 & 67.42 \\
5 & 49.98 & 50.02 & 33.58 & 66.42 \\
6 & 47.08 & 52.92 & 22.28 & 77.72 \\
7 & 51.27 & 48.73 & 28.26 & 71.74 \\
8 & 53.22 & 46.78 & 29.57 & 70.43 \\
9 & 53.66 & 46.34 & 34.16 & 65.84 \\
\hline
\end{tabular}

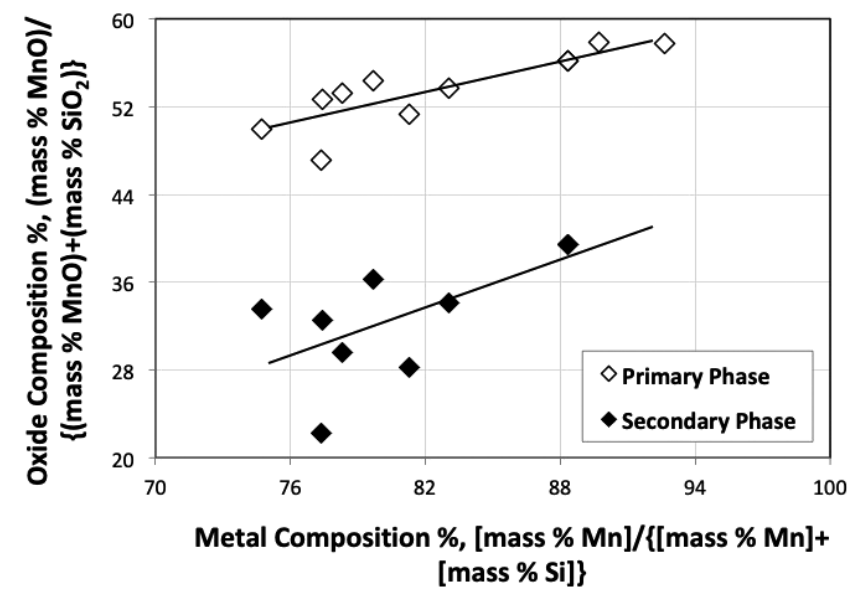

Fig. 8. Inclusion composition after isothermal heating at the solid-liquid equilibrium temperature.

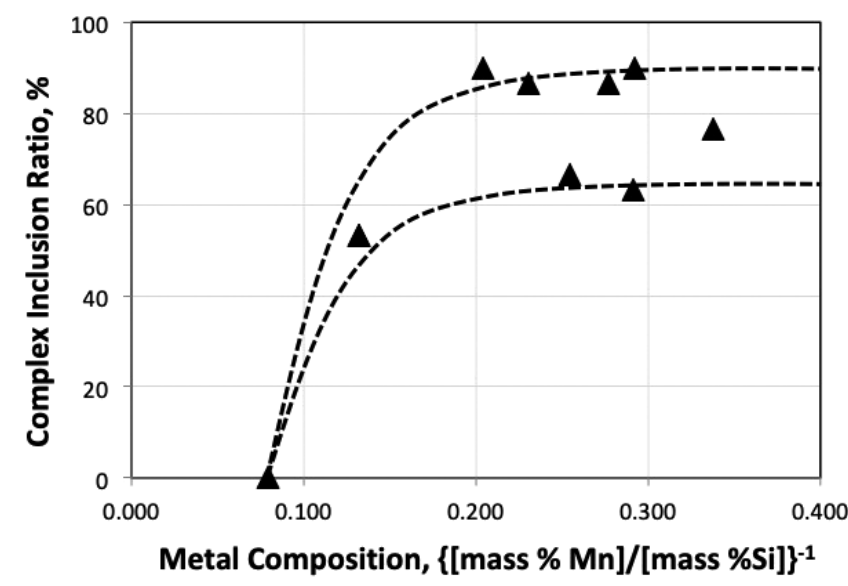

Fig. 9. Complex inclusion formation ratio as a function of manganese to silicon mass ratio in the alloy.

steel. At a very high manganese mass ratio, the secondary inclusion phase failed to precipitate, indicating that the formation of a secondary phase by holding at the solid-liquid equilibrium temperature occurs only below a certain manganese ratio. As demonstrated in Fig. 9, in order to achieve a complex inclusion formation ratio of greater than about $60 \%$, manganese to silicon ratio of 4.91 in the metal phase

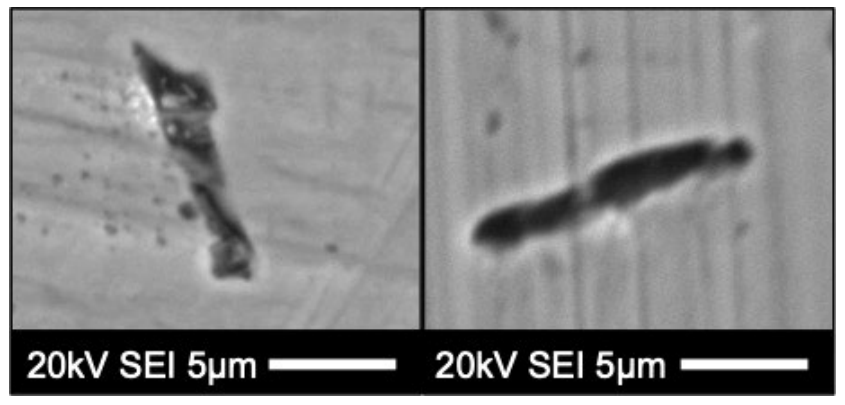

Fig. 10. SEM image of typical independent $\mathrm{SiO}_{2}$ inclusions.

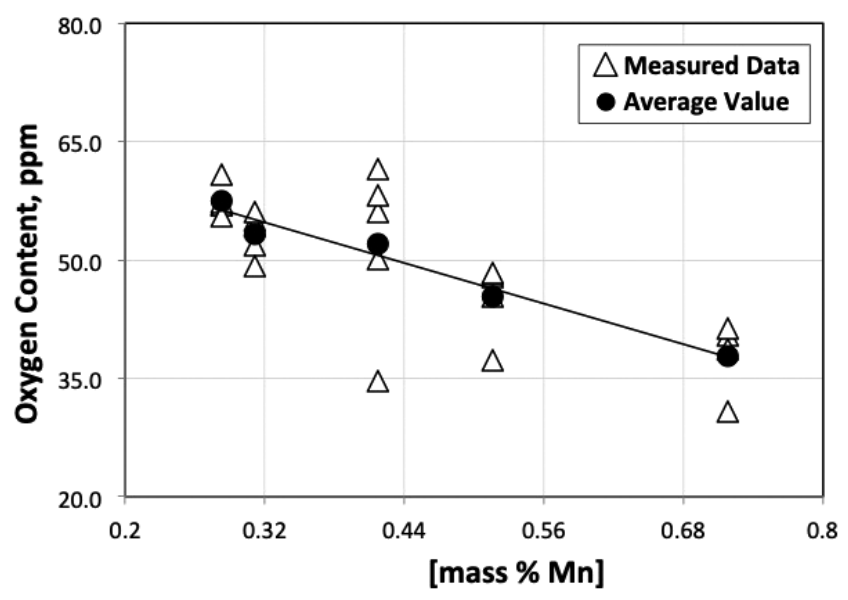

Fig. 11. Dissolved oxygen content in the metal phase with varying Mn addition.

is necessary. This value was determined as the reciprocal of the abscissa of Fig. 9 at about $60 \%$ complex inclusion formation ratio. Complex inclusion ratio was calculated as the ratio of the number of inclusions with $\mathrm{SiO}_{2}$ precipitation to the total number of inclusions observed. Above this value, fewer complex inclusions with a $\mathrm{SiO}_{2}$-rich secondary inclusion phase form. Hence, controlling silicon and manganese ratios in the alloy may regulate the formation of the complex inclusions in $\mathrm{Si}-\mathrm{Mn}$ deoxidized steel.

On the other hand, beside the spherical $\mathrm{MnO}-\mathrm{SiO}_{2}$ inclusions, independent $\mathrm{SiO}_{2}$ inclusions were also observed in the prepared Si-Mn deoxidized alloys, as shown in Fig. 10. These inclusions were shaped irregularly and distributed homogeneously throughout the metal phase.

The oxygen concentration in steel was also found to decrease with the addition of manganese at a relatively constant silicon content, as described in Fig. 11. The experimental data therefore confirms the theoretically expected increase in deoxidation efficiency using complex $\mathrm{Si}-\mathrm{Mn}$ deoxidation. This is extremely beneficial in terms of minimizing the oxygen content in steel to prevent blowholes and achieve cleaner steel.

\section{Discussion: Proposed Inclusion Formation Mecha- nism}

The evolution of a complex-type inclusion during isothermal heating at the solid-liquid equilibrium temperature can be explained in terms of microsegregation in the alloy. A similar phenomenon has been previously observed in $\mathrm{Si}-\mathrm{Mn}$ deoxidized steel as a result of long local solidification time 
and slow cooling rate where secondary MnS inclusion precipitated on primary manganese-silicate inclusion. ${ }^{5)} \mathrm{Kang}$ et al. explained this phase transformation during cooling in terms of the mass transfer between the metal and oxide phase as a result of decreased oxygen solubility in steel. ${ }^{4)}$

The detailed mechanism of inclusion formation at the solid-liquid equilibrium temperature can be divided into three steps: 1) the formation of primary inclusions 2) the nucleation of secondary inclusions and 3) the growth and coalescence of inclusions. These three steps are summarized schematically in Fig. 12.

\subsection{Formation of Primary Inclusions}

Initially, above the liquidus temperature when the steel is in a completely molten state, primary manganese silicate inclusions formed as a consequence of the deoxidation process. This was confirmed by plotting the measured composition values on the $\mathrm{MnO}-\mathrm{SiO}_{2}$ binary phase diagram as illustrated in Fig. 13. In this step, primary inclusions grow predominantly by collision and agglomeration. In the case of liquid inclusions, this is expected to result in spherical inclusions, as manifested by the spherical morphology of the observed inclusions shown earlier in Fig. 6. ${ }^{31}$

\subsection{Nucleation of Secondary Inclusions}

As the molten alloy was held isothermally at the solidliquid equilibrium temperature, the nucleation of $\mathrm{SiO}_{2}$-rich secondary inclusions can be explained from the perspective of microsegregation. The microsegregation phenomenon results from the uneven distribution of solutes in the solid and molten steel. The initial solidification of the alloy starts when the temperature of the molten alloy reaches the liquidus. As it is further cooled, the composition of the liquid phase changes according to the liquidus curve and the composition of the solid phase changes according to the solidus curve. Due to the uneven partition of the solute elements in the solid and liquid alloy, enriched solute concentrations in the liquid phase lead to the nucleation of secondary inclusions. ${ }^{1)}$

The fundamental cause of this is the difference between the thermodynamic equilibrium solubility of the alloying elements in the different phases that coexist during solidification. Another factor is the inability of solid-state diffusion to bring the composition to equilibrium levels after solidification is complete, due to the short cooling times and small diffusion coefficients involved. ${ }^{33)}$ Moreover, the solubility of oxygen in liquid steel also decreases with temperature. Hence, oxygen is expected to move from the molten steel to form additional oxides. In this case, the steel matrix became saturated with silicon and it began to precipitate out from the steel by reacting with the excess oxygen. Secondary inclusions that precipitated out of the molten steel were manifested by the darker secondary $\mathrm{SiO}_{2}$-rich inclusion.

\subsection{Growth and Coalescence of Inclusions}

Finally, while holding the alloy isothermally at the solid-liquid equilibrium temperature, existing inclusions began to grow and coalesce due to natural convection in the molten alloy. Inclusions remained in a constant state of motion causing collision and aggregation of the primary and secondary inclusions to form larger complex inclusions. ${ }^{34)}$ Some inclusions remain in single state while some become attached to another inclusion and end up as a complex inclusion. As was observed experimentally, the complex inclusion that formed in this study was composed of a primary $\mathrm{MnO}-\mathrm{SiO}_{2}$ phase and a secondary $\mathrm{SiO}_{2}$-rich phase.

Based on this mechanism, the inclusions that form in $\mathrm{Si-Mn}$ deoxidized steel held isothermally at the solid-liquid

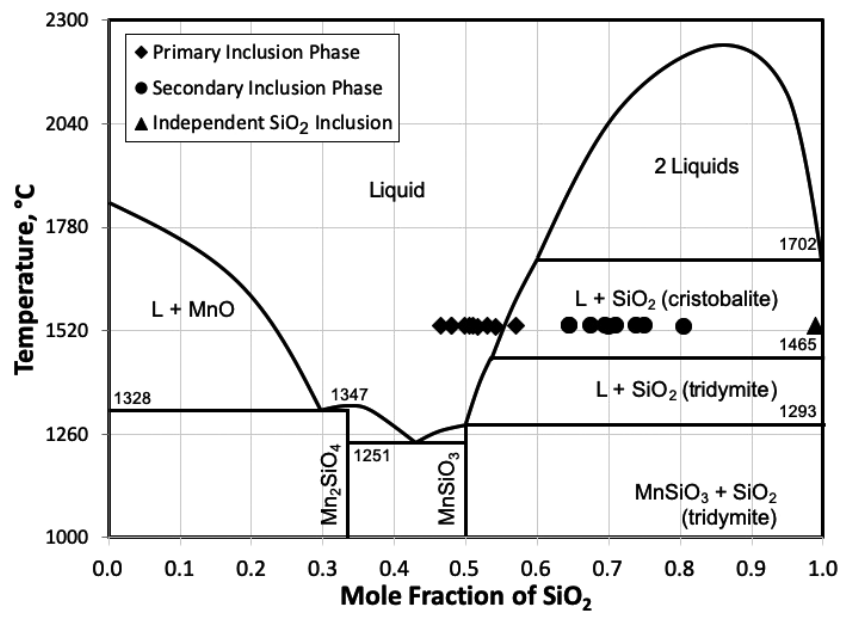

Fig. 13. Optimized $\mathrm{MnO}-\mathrm{SiO}_{2}$ phase diagram. ${ }^{28)}$
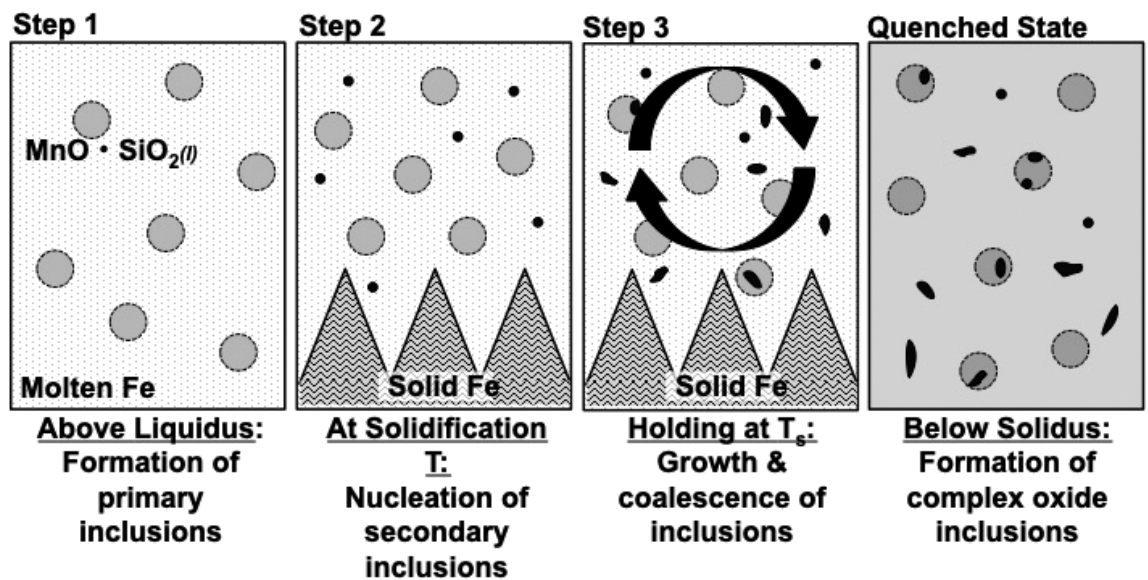

Fig. 12. Graphical representation of the proposed mechanism of inclusion formation at the solid-liquid equilibrium temperature. 
equilibrium temperature may be summarized into three types: a) primary $\mathrm{MnO}-\mathrm{SiO}_{2}$ inclusions that formed at the liquid state b) secondary $\mathrm{SiO}_{2}$ inclusions that precipitated at the solid-liquid equilibrium temperature and c) complex inclusions with both primary $\mathrm{MnO}-\mathrm{SiO}_{2}$ inclusions and secondary $\mathrm{SiO}_{2}$ inclusions formed by agglomeration of existing inclusions.

\section{Conclusion}

This study was an investigation of the formation of complex inclusions, distributed homogeneously throughout the alloy, with a $\mathrm{SiO}_{2}$-rich secondary phase by isothermal heating at the solid-liquid equilibrium temperature. Holding at the solid-liquid equilibrium temperature was found to promote the formation of a complex inclusion composed of a $\mathrm{MnO}-\mathrm{SiO}_{2}$ primary phase and $\mathrm{SiO}_{2}$-rich darker secondary phase. The difference in the average size of the complex inclusions and the single-phase inclusions was deemed to be insignificant in terms of its influence to the properties of the alloy.

Increased manganese addition to the alloy was found to decrease the oxygen content in the alloy and also lead to a decrease in the $\mathrm{SiO}_{2}$ content in both the primary and secondary inclusion phase. In addition, above a critical manganese to silicon ratio in the metal phase, the secondary inclusion phase failed to form. Considering these results, the development of a complex inclusion with a $\mathrm{SiO}_{2}$-rich secondary phase was attributed to microsegregation in the alloy as the solute elements became saturated in molten steel while holding at the solid-liquid equilibrium temperature. The formation of complex inclusions by the coalescence of primary and secondary inclusions was confirmed in this study.

\section{Acknowledgements}

The authors gratefully acknowledge Japanese Government Ministry of Education, Culture, Sports, Science and Technology (MEXT) for the corresponding author's financial support during her graduate studies. Recognition is also extended to Professor Takehito Hiraki, Professor Yasushi Sasaki and Professor Elizabeth Webeck for their valuable help and encouragement.

\section{REFERENCES}

1) D. You, S. Michelic, P. Presoly, J. Liu and C. Bernhard: Metals, 7 (2017), 460

2) A. Kazakov: Proc. Microscopy \& Microanalysis 2016 Meeting, Microscopy Society of America, Washington, (2016), 1938.

3) E. T. Turkdogan: BOF Steelmaking, Volume 2 Theory, ed. by R Pehlke et al., Iron and Steel Society of AIME, New York, (1975), 165.

4) Y. B. Kang and H. G. Lee: ISIJ Int., 44 (2004), 1006.

5) H. S. Kim, H. G. Lee and K. S. Oh: ISIJ Int., 42 (2002), 1404

6) S. Vantilt, B. Coletti, B. Blanpain, J. Fransaer, P. Wollants and S. Sridhar: ISIJ Int., 44 (2004), 1.

7) K. Tomioka, K. Ogawa and H. Matsumoto: ISIJ Int., 36 (1996), S101.

8) H. Cengizler and R. H. Eric: Proc. 10th Int. Conf. on Molten Slags, Fluxes and Salts, The Minerals, Metals and Materials Society, Pittsburgh, PA, (2016), 1309.

9) S. Kobayashi: ISIJ Int., 39 (1999), 664.

10) H. Amitani, K. Morita and N. Sano: ISIJ Int., 36 (1996), S26.

11) M. Ito, K. Morita and N. Sano: ISIJ Int., 37 (1997), 839.

12) X. J. Zhuo, Y. Q. Wang, X. H. Wang and H. G. Lee: J. Iron Steel Res. Int., 17 (2010), 10.

13) R. A. Ricks, P. R. Howell and G. S. Barritte: J. Mater. Sci., 17 (1982), 732.

14) H. S. Kim, H. G. Lee and K. S. Oh: Metall. Mater. Trans. A, 32 (2001), 1519.

15) H. S. Kim, C. H. Chang and H. G. Lee: Scr. Mater., 53 (2005), 1253.

16) H. S. Kim, H. G. Lee and W. G. Jung: ISIJ Int., 40 (2000), S82.

17) T. Fujisawa, M. Nomura and H. Sakao: Trans. Iron Steel Inst. Jpn., 21 (1981), 624.

18) Z. Liu, J. Wei and K. Cai: ISIJ Int., 42 (2002), 958.

19) M. Wintz, M. Bobadilla, J. Lehmann and H. Gaye: ISIJ Int., 35 (1995), 715.

20) T. Fujisawa, K. Imaoka and H. Sakao: Trans. Iron Steel Inst. Jpn., 21 (1981), 559.

21) M. Hino and K. Ito: Thermodynamic Data for Steelmaking, Tohoku University Press, Sendai, (2010), 168.

22) C. Wagner: Thermodynamics of Alloys, Addison-Wesley, Cambridge, MA, (1952), 47.

23) K. P. Abraham, M. W. Davies and F. D. Richardson: J. Iron Steel Inst., 196 (1960), 82

24) H. Schenck, M. G. Frohberg and T. El Gammal: Arch. Eisenhuttenwes., 32 (1961), 509.

25) S. R. Mehta and F. D. Richardson: J. Iron Steel Inst., 203 (1965), 524.

26) H. Fujita and S. Maruhashi: Tetsu-to-Hagané, 56 (1970), 830 (in Japanese).

27) D. R. Gaskell: Metall. Trans., 5 (1974), 776

28) The 19th Committee on Steelmaking, The Japan Society for the Promotion of Science: Steelmaking Data Sourcebook, Gordon and Breach Science Publishers, New York, (1988), 285.

29) K. Takahashi and M. Hino: High Temp. Mater. Process., 19 (2000), 1 .

30) N. Anmark, A. Karasev and P. G. Jonsson: Materials, 8 (2015), 751.

31) J. Campbell: Castings: The New Metallurgy of Cast Metals, 2nd ed., Elsevier, Burlington, MA, (1991), 172.

32) Y. M. Kim and I. H. Jung: Metall. Mater. Trans. A, 46 (2015), 2736.

33) Y. M. Won and B. Thomas: Metall. Mater. Trans. A, 32 (2001), 1755.

34) Y. Xu, Y. G. Wu, C. J. Zhang and L. G. Zhu: J. Iron Steel Res. Int., 22 (2015), 804. 